DOI: $10.30612 /$ re-ufgd.v4i8.8123

\title{
MEMÓRIA E TRAJETO SECULAR: OS TERENA COMO PROTAGONISTA DE SUA HISTÓRIA
}

Memory and secular path: the Terena as a protagonist of his history

\author{
Rosalvo Ivarra Ortiz ${ }^{1}$ \\ Noêmia dos Santos Pereira Moura ${ }^{2}$
}

Resumo: O presente artigo possui como objetivo apresentar duas situações de protagonismo Terena na luta pela terra ao longo do século XX e historiar o movimento Terena em defesa de seus direitos. A metodologia utilizada foi à história oral e a etnografia (trabalho de campo), portanto um diálogo entre a História Indígena e a Antropologia. Os resultados apresentados foram de intensa movimentação dos indígenas para recuperação de seus territórios tradicionais. As duas situações reivindicativas em destaque demonstram que essa etnia e seus "guerreiros" (autodenominação dos homens que vão para frente dos embates com os fazendeiros) estão dispostos a retomar seus territórios, ao menos esses dos quais não se apartaram, para dar continuidade ao seu jeito de ser Terena. Os Terena atuais, pelo que pudemos perceber, foi tomando consciência de seu lugar social na sociedade brasileira. A partir desse movimento foram traçando novas estratégias políticas para ocupar novos espaços sócio-políticos. A arte da dissimulação faz parte do conjunto de táticas de negociação dos Terena e é amplamente utilizada pelas lideranças. Essas costumam concordar e aceitar as propostas que lhes são feitas em espaços não-indígenas de poder. Muitas vezes se comprometem a desenvolver as atividades propostas que lhes são favoráveis. Ou seja, concordam e se propõem a executar as atividades desde que sua população o aceite. Entretanto, se o grupo de apoio na aldeia discordar dos encaminhamentos propostos, simplesmente engaveta o projeto e suas ações.

Palavras-chaves: Protagonismo. Movimento indígena. Territórios.

Abstract: The present article aims to present two situations of Terena protagonism in the struggle for land throughout the twentieth century and to historicize the Terena movement in defense of their rights. The methodology used was oral history and ethnography (field work), therefore a dialogue between Indigenous History and Anthropology. The results presented were of intense movement of the natives for the recovery of their traditional territories. The two prominent protest situations demonstrate that this ethnic group and its "warriors" are ready to return to their territories, at least those of which they did not separate, to continue its way to be Terena. The present Terena, for what we could perceive, was becoming aware of its social place in Brazilian society. From this movement were traced new political strategies to occupy new socio-political spaces. The art of dissimulation is part of Terena's set of negotiating tactics and is widely used by leaders. These tend to agree and accept the proposals made to them in non-indigenous spaces of

\footnotetext{
${ }^{1}$ Possui graduação em Licenciatura plena em Ciências Sociais pela Faculdade de Ciências Humanas da Universidade Federal da Grande Dourados- FCH/UFGD. Atualmente é acadêmico do Mestrado em Antropologia Sociocultural pela mesma instituição de ensino. É membro do grupo de pesquisa GIPEDAS - "Grupo Iberoamericano para Pesquisa e Difusão da Antropologia Sócio-Cultural" vinculado à Universidad de Salamanca- Espanha (USAL). Bolsista: FUNDECT. E- mail: rosalvortiz@hotmail.com

${ }^{2}$ Professora Adjunta IV da UFGD, licenciada e mestre em História com ênfase em História Indígena (UFMS), doutora em Ciências Sociais/Etnologia (UNICAMP). Coordenadora Institucional PIBID/UFGD. Pesquisadora na etnia Terena. E-mail: noemiamoura@ufgd.edu.br
} 
power. Often they undertake to carry out the proposed activities that are favorable to them. That is, they agree and propose to carry out the activities as long as their population accepts them. However, if the support group in the village disagrees with the proposed referrals, it simply misleads the project and its actions.

Keywords: Protagonism. Indigenous movement. Territories.

\section{O Protagonismo Terena e Contexto Histórico}

No Mato Grosso do Sul, os Terena produziram duas modalidades de aldeamento: urbano e o rural. Estamos designando aldeamento rural as Terras Indígenas e aldeamentos urbanos as "aldeias" ou "bairros" localizados nas cidades. Os aldeados em áreas urbanas estão organizados em Campo Grande, Capital do Estado - na Aldeia Marçal de Souza e outras quatro aldeias, no município de Anastácio - na Aldeia Aldeinha ${ }^{1}$ e em Sidrolândia - na Aldeia Tereré. Todavia, é importante corroborar que a mobilidade de indivíduos e famílias Terena no território brasileiro é intensa, ao ponto de nos depararmos com indivíduos dessa etnia em vários estados do país. Talvez possamos afirmar que os atuais Terena sejam o resultado de vários encontros entre os povos Aruak e outros grupos étnicos indígenas e nãoindígenas e sua etnicidade é um construto resultante desses diversos contatos. Contudo, alguns elementos ainda os identificam com a família lingüística Aruak, como por exemplo a abertura para a negociação.

A partir da década de 1970, os Terena, bem como vários outros povos indígenas, começaram a se fortalecer politicamente, através do movimento indígena, bem como das associações internas e externas, com indígenas e não-indígenas. Reconhece-se essa iniciativa como o processo de fortalecimento da participação política indígena na sociedade brasileira (MOURA, 2001; SANT'ANA, 2004; FERREIRA, 2004).

A principal bandeira do movimento indígena brasileiro ${ }^{2}$ é a luta pela terra. O campo político, no qual se estabelecem as relações entre peritos, etnia, tribunais e proprietários das terras reivindicadas são conflituosos. Todos os atores sociais em destaque se engajam na produção de provas que lhes garantam determinado território. Os

\footnotetext{
${ }^{1}$ Aldeinha é a primeira aldeia urbana do Brasil. Em 1933 foi fundada por um grupo de Terena que se deslocavam da Aldeia de Buriti para a Aldeia de Cachoeirinha devido a conflitos internos. Em 1965, com a criação do município de Anastácio (antiga Margem Esquerda do Rio Aquidauana, município homônimo ao rio), a Aldeia fora impactada pelo processo de urbanização. Em 1986, sentindo-se ameaçadospela possibilidade de desterritorialização, os Terena se organizaram aos moldes de uma aldeia rural (MOURA, 1994).

2 Para Luciano (2006:58) Movimento Indígena "é o conjunto de estratégias e ações que as comunidades e as organizações indígenas desenvolvem em defesa de seus direitos e interesses coletivos." Salienta ainda que para ser incluído neste movimento baste o indígena pertencer formalmente a uma aldeia ou organização indígena e produzir ações, aspirações e projetos voltados para as populações indígenas.
} 
fazendeiros com seus assessores (advogados, antropólogos, historiadores, etc.) buscam o maior número de indícios para continuar a desfrutar dos títulos adquiridos. Os indígenas, através de suas lideranças, promovem reuniões e indicam provas a serem utilizadas pelos peritos e ficam, constantemente, à disposição desses. Os juízes aguardam um laudo bem fundamentado que os instrumentalize no julgamento da questão.

Os Terena acompanham passo a passo o trabalho dos peritos, desde sua chegada até sua saída da área indígena. Indígenas esses que, na primeira metade do século passado, estavam fadados a desaparecer, segundo seus estudiosos e protetores. Chegaram à segunda metade em número cada vez mais crescente quantitativa e politicamente. Apropriaram-se dos saberes nos âmbitos das instituições políticas, da legislação e dos espaços sociais produzidos pela sociedade brasileira relativos à educação, a saúde, ao trabalho, à segurança e ao lazer, nos quais passaram a circular e intervir. Aprenderam a transitar nos espaços da sociedade brasileira, porém continuam reproduzindo seus códigos de civilidade interna e externamente às suas aldeias (AZANHA, 2004).

Todo esse movimento tem início ainda no século XIX, porém a legislação indigenista vigente naquele contexto era totalmente adversa aos povos indígenas (CUNHA, 1992).
Vejamos como os Terena vêm ao longo do século XX desenvolvendo táticas de recuperação dos territórios que consideram serem tradicionais para sua etnia.

Os Terena estão presentes na região do Baixo Pantanal (atual Mato Grosso do Sul) desde a segunda metade do século XVIII. Durante o conflito platino entre o Brasil e o Paraguai (1864-70), no século seguinte a sua fixação em aldeamentos missionários católicos e aldeamentos menores espontâneos, deixaram seus territórios, os quais reconheciam como tradicionais, refugiando-se nas encostas da Serra de Maracaju. Ao retornar, após o término da guerra, se depararam com uma nova situação territorial. Suas antigas aldeias abrigavam excombatentes que se valiam de suas patentes de guerra para negociar com o governo do Estado de Mato Grosso. A partir de então, algumas lideranças Terena iniciaram verdadeiras cruzadas para recuperar suas antigas posses (MOURA, 2009).

Dado o limite dessa investigação, destacamos apenas duas situações reivindicativas dessa etnia. A primeira ocorreu na época em que o Marechal Cândido Mariano Rondon estava desenvolvendo atividades integracionistas na região de Mato Grosso, no início do século XX. E a segunda foi marcada pelo processo de ampliação da Terra Indígena Taunay/Ipegue, cujo início se 
deu em 1985. Portanto, uma localizada no início do século e a outra em suas décadas finais.

No final do século XIX, alguns agrupamentos de famílias terena, cujos assentamentos remontam as décadas de 1860 , continuaram mantendo intenso contato com os governos estaduais e federal. Seus capitães, que estiveram diretamente envolvidos nas disputas fronteiriças ao lado do Brasil, exibiam seus uniformes e patentes nas incursões que faziam rumo à sede do governo federal para reivindicar a retomada de suas antigas aldeias.

O Capitão José Pedro (Pirainha), o Capitão Alexandre Bueno (Naxe-Daxe) e o Capitão Joaquim Victorino (Brejão), são alguns líderes Terenas que promoveram encontros e negociações com o governo brasileiro. Em um trecho de sua "Mudança Cultural Terena", Altenfelder Silva (1949) registra os aldeamentos Terenas no território denominado Miranda, no pós-guerra.

Pouco após a campanha do Paraguai, habitavam os Terena, segundo eles próprios informam, as seguintes aldeias: Ipegue(em área compreendida entre as atuais aldeias de Ipegue e Bananal); Imokovookoti(nas imediações da atual aldeia de Cachoeirinha); Tuminiku(nas proximidades da atual aldeia de Bananal); Coxi(próxima ao córrego de Taquarí); Naxe-Daxe (nas proximidades do córrego do mesmo nome); Háokoé( nome Terena para a fruta do pindó; situava-se a aldeia a uma légua de Tuminiku); Moreirae Akuleá(ambas nas proximidades de
Miranda); Kamakuê(próxima à atual aldeia de Duque Estrada); Brejão(próxima a Nioaque); LimãoVerde(próxima a Aquidauana); Cerradinho(na área do atual Município de Campo Grande). Nessa época estimavam-se os Terena entre 3 e 4 mil. (SILVA, p. 281, 1949).

O Terena Joaquim Victorino que habitava a aldeia de Naxe Daxe, na região de Miranda, tornou-se conhecido como Capitão Vitorino, quando da perda das terras dessa aldeia para os fazendeiros naquela região. Transferiu-se junto com demais Terena para a região de Nioaque, constituindo muito tempo depois a Reserva Indígena de Brejão (Capitão Vitorino). "Já antes, em 20 de março de 1883, o Diretor dos Índios das Aldeias do município de "Miranda", Antonio Xavier Castello, o nomeará [Capitão Vitorino] para chefe da Aldeia "Naxe Daxe", que foi depois invadida e demarcada para fazenda de particular, como si isso não constituísse uma iniquidade! Aquella aldeia fôra visitada em 1866 por Taunay" (HORTA BARSOSA, 1924, p. 10) (grifo nosso).

Segundo o referido relatório Naxe Daxe foi invadida desde 1883 e seus habitantes deslocaram-se para Brejão no município de Nioaque. Capelinha também deixou de existir como aldeia. Assim como Agachi tornou-se, propriedade particular. Os índios - Kinikináo - que ali se encontravam foram transferidos para outras localidades. Os referidos indígenas perderam suas terras, consideradas devolutas, para Antonio Leopoldo Pereira 
Mendes, que dali os expulsou em 1908, mais ou menos, como fico evidente no trecho a seguir "Existem alli uns 15 índios que pretendem se mudar para o Posto de Lalima, já tendo muitos delles para alli se mudado" (FUNAI, 1925).

Após a constatação da perda de seu antigo território, as lideranças Terena procuraram salvaguardar os limites nos quais passaram a viver, conforme citação acima de Altenfelder Silva. Dessa feita, na passagem de Rondon por Mato Grosso, teceram reclamações a respeito de suas relações com os regionais e denunciaram os esbulhos cartoriais produzidos pelo Estado de Mato Grosso, juntamente com os fazendeiros titulados proprietários. Reconheceram o Rondon como representante do governo federal e o governo, por sua vez, incumbiu o militar de realizar a demarcação da área indígena de Taunay/Ipegue e Cachoeirinha no ano de 1905, antes mesmo da criação do Serviço de Proteção ao Índio (1910).

Com o processo de territorialização produzido pelo governo brasileiro, os Terena começaram a povoar as reservas de Cachoeirinha e Taunay/Ipegue. Reproduziram paulatinamente sua forma de organização espacial criando internamente várias aldeias. Atualmente, a Terra Indígena de Taunay/Ipegue está dividida em sete aldeias (Bananal, Água Branca, Morrinho, Imbirussú,
Lagoinha, Ipegue e Colônia Nova), cuja população é de mais ou menos 4.161 habitantes.

Em 1985, as lideranças Terena de Taunay/Ipegue ingressaram uma ação na FUNAI requerendo a ampliação da reserva de 6.461 para 30.000 hectares mais ou menos. As fazendas no entorno foram tidas como dentro do território tradicional dessa etnia. Desde então, os proprietários começaram um movimento para impedir a mobilidade indígena dentro de seus limites. Os anciãos indígenas reconstroem o mapa territorial dos Terena através da memória de locais sagrados, locais de coleta de frutos, pesca e caça de animais silvestres. Tomam os cursos d'água como limites naturais. Entretanto, na época da seca os marcos naturais, praticamente, desaparecem. Justificam o movimento pela terra como sendo uma forma de preservação do modus vivendi e da identidade étnica.

Da mesma forma que os Terena se organizam, os fazendeiros, por seu turno, contratam historiadores e antropólogos para fazerem as suas defesas. No caso acima destacado a querela se estende por mais de duas décadas. Entretanto, no ano de 1999, os Terena recuaram no processo de ampliação aceitando a homologação da atual área de seis mil e poucos hectares. Explicam que naquele momento, a melhor tática era recuar para garantir aquele chão para seus filhos e netos 
para em seguida reatualizar a demanda da ampliação. Anos depois, recomeçam o movimento de reocupação das terras das fazendas circunvizinhas.

Demonstram que as fazendas foram abertas pelas mãos Terena, bem como as cercas foram eles que construíram. Muitos como o Cacique de Imbirussú, o Sr. Jurandir, se lembra quando há quase trinta anos atrás auxiliou seu pai na construção da cerca da Fazenda Cristalina. Identificam locais sagrados como o cemitério que havia na referida fazenda, o qual foi destruído pelas máquinas que abriram as invernadas para a criação de gado bovino.

O processo de ampliação está aberto e recentemente foi instrumento de uma Inspeção Judicial acompanhado por todas as partes interessadas. Os Terena são categóricos ao afirmar que nunca abriram mão de seu território tradicional, pois nunca se afastaram das fazendas, nas quais trabalhavam como peões, changueiros e lavradores. Só muito recentemente, foram impedidos de ultrapassar as cercas das propriedades privadas.

As duas situações reivindicativas em destaque demonstram que essa etnia e seus "guerreiros" (autodenominação dos homens que vão para a frente dos embates com os fazendeiros) estão dispostos a retomar seus territórios, ao menos esses dos quais não se apartaram, para dar continuidade ao seu jeito de ser Terena.

Portanto, os Terena atuais, pelo que pudemos perceber, foram tomando consciência de seu lugar social dentro da sociedade brasileira. A partir desse movimento foram traçando novas estratégias políticas para ocupar novos espaços sóciopolíticos. A arte da dissimulação faz parte do conjunto de táticas de negociação dos Terena e é amplamente utilizada pelas lideranças. Essas costumam concordar e aceitar as propostas que lhes são feitas em espaços nãoindígenas de poder. Muitas vezes se comprometem a desenvolver as atividades propostas que lhes são favoráveis. Ou seja, concordam e se propõem a executar as atividades desde que sua população as aceite. Entretanto, se o grupo de apoio na aldeia discordar dos encaminhamentos propostos, simplesmente engaveta o projeto e suas ações.

Por fim, a dissimulação é uma maneira de deixar de fazer aquilo com o que não se identificam ou que avaliam não ser útil para a aldeia. Dessa forma, Certeau (1994) diria que essa é uma ação reflexiva daqueles grupos subalternos que subvertem a ordem imposta ao invés de submeter-se totalmente. Ao passo que o não-índio espera a rendição e a submissão, os indígenas metaforizam a ordem dominante, fazendo funcionar as suas leis e suas representações num outro registro, no 
quadro de sua própria tradição. $\mathrm{O}$ autor de $A$ Invenção do Cotidiano fala de microliberdades e micro-poderes produzidos pelos que não detém a hegemonia política, no caso em questão os Terena.

\section{Referências}

SILVA, F. A. Mudança Cultural dos Terena. Revista do Museu Paulista, .São Paulo, nº 8, V. III, 1948.

AZANHA, G. As Terras Indígenas Terena no Mato Grosso do Sul. Revista de Estudos e Pesquisas, FUNAI, Brasília, v.2, n.1, p.61-111, jul. 2004

CERTEAU, M. A Invenção do Cotidiano: 1. Artes de fazer. Rio de Janeiro: Vozes, 1994.

CUNHA, M. C. Legislação indigenista do século XIX - Uma compilação (1808-1889). São Paulo: EDUSP: Comissão Pró-Índio de São Paulo, 1992.

FERREIRA, A. C. Tutela e Resistência Indígena: Etnografia e História das Relações de Poder entre os Terena e o Estado Brasileiro. Tese de Doutorado em Antropologia Social. Museu Nacional; Universidade Federal do Rio de Janeiro, 2007.

FUNAI. Relatório de 1925, apresentado para o Senhor Doutor José Bezerra Cavalcante Director do Serviço de Proteção aos Índios. Microfilme 379, fotg. 1600-1614, DEDOC, Arquivo da FUNAI, Brasília).

HORTA BARBOSA, N. B. Memorial relativo à demarcação das Terras de Brejão. Campo Grande, 1924, 27 pp. In: Processo 1059/82, CGAF, FUNAI, Brasília.

LUCIANO, G. J. dos S. O Índio Brasileiro: O que você precisa saber sobre os povos indígenas no Brasil de Hoje. 1. ed. Brasília: MEC/SECAD MUSEU NACIONAL/UFRJ, 2006. v. 1. 232p .

MOURA, N. S. P. O Processo de Terenização do Crisitanismo na Terra Indígena TAUNAY/IPEGUE no século XX. Doutorado em Ciências Sociais, UNICAMP-SP, 2009.

SANT'ANA, G. R. A Dinâmica do associativismo Terena no espaço Urbano. Marília, SP, Dissertação de Mestrado em Ciências Sociais, 2004. (não publicada). 